\title{
Expression of Concern
}

\section{Expression of Concern: Palazuelos et al., "TACE/ADAM17 is Essential for Oligodendrocyte Development and} CNS Myelination"

JNeurosci is publishing an Expression of Concern for the article, "TACE/ADAM17 Is Essential for Oligodendrocyte Development and CNS Myelination," by Javier Palazuelos, Howard C. Crawford, Michael Klingener, Bingru Sun, Jason Karelis, Elaine W. Raines, and Adan Aguirre, which appeared on pages 11884-11896 of the September 3, 2014 issue. The editors have been made aware of questions about the reliability of the data presented in Figure $3 K-M$, Figure 4, $J$ and $K$, and Figure 5, E and J. JNeurosci will make a final decision on this article pending a full investigation and reproduction of results and conclusions presented in the article.

DOI: 10.1523/JNEUROSCI.0611-21.2021 